\title{
Modal analysis of sandwich panel with composite laminated faces
}

\author{
Eva Kormanikova \\ Department of Structural Mechanics, Technical University of Kosice, Košice, Slovakia \\ E-mail: eva.kormanikova@tuke.sk
}

Received 15 March 2019; accepted 22 March 2019

DOI https://doi.org/10.21595/vp.2019.20658

Check for updates

Copyright $(2019$ Eva Kormanikova. This is an open access article distributed under the Creative Commons Attribution License, which permits unrestricted use, distribution, and reproduction in any medium, provided the original work is properly cited.

\begin{abstract}
A sandwich panel with laminate faces was used for free vibration analysis. The Shear Deformation Theory is considered for analysis. The effect of sandwich design parameters such as core thickness and fiber reinforced angle on vibration response is investigated. The modal analysis for various lengths of sandwich panel is done to find the limit length of the panel, which is sensitive to dynamic wind load.
\end{abstract}

Keywords: sandwich panel, mode shape, natural frequencies, limit length.

\section{Introduction}

Sandwich panels are one of very important group of laminated composites. They consist of two thin faces with thickness of $h_{1}$ and $h_{3}$ and a core with thickness of $h_{2}$. The faces are made of high strength materials having good properties under tension, such as fiber reinforced polymer matrix laminates used in this paper, while the core is made of lightweight materials such as foam, having good properties under compression. Sandwich composites combine lightness and flexural stiffness [1].

The analysis of simple sandwich structures may be achieved by analytical methods, by adapting the classical tools of structural analysis on anisotropic elastic structure face elements. For more complex structures, such as more general boundary conditions or loading, numerical methods such as Finite Element Method, Boundary Element Method, etc. are used [2-5].

The use of assumptions is necessary to mathematical modeling of laminated composites. These include an elastic behavior of fibers and matrices, a perfect bonding between fibers and matrices, low variation of the mechanical characteristics of the individual fibers, uniform fiber diameters, their regular arrangement in the matrix, etc.

Taking into account the different size scales of mechanical modelling of structure elements composed of fiber reinforced composites, the micro, macro and structural modeling levels must be considered [6-10].

\section{First-order shear deformation theory (FSDT)}

FSDT considers that transverse normal do not remain perpendicular to the midsurface after deformation. This theory is used for thicker plates or sandwiches taking into account the Reissner kinematics (Fig. 1).

Transverse shear stresses are added to the state of plane stress for this reason. Shear deformations are written following the Fig. 2:

$$
\begin{aligned}
& \gamma_{x z 2}=\left(\frac{u_{12}-u_{32}}{h_{2}}+\frac{\partial w}{\partial x}\right)=\left(\frac{u_{1}-u_{3}}{h_{2}}+\frac{d}{h_{2}} \frac{\partial w}{\partial x}\right), \\
& \gamma_{y z 2}=\left(\frac{v_{12}-v_{32}}{h_{2}}+\frac{\partial w}{\partial y}\right)=\left(\frac{v_{1}-v_{3}}{h_{2}}+\frac{d}{h_{2}} \frac{\partial w}{\partial y}\right),
\end{aligned}
$$

where $d$ is midplane distance of sandwich faces: 
$d=h_{2}+\frac{h_{1}+h_{3}}{2}$

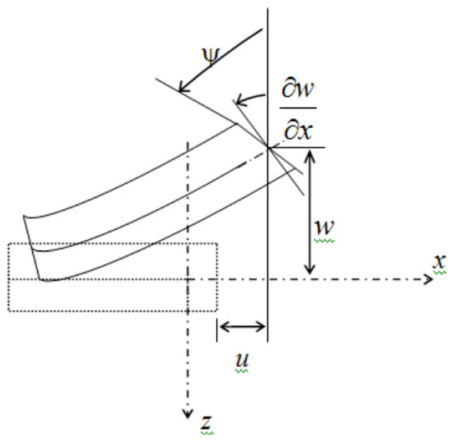

a)

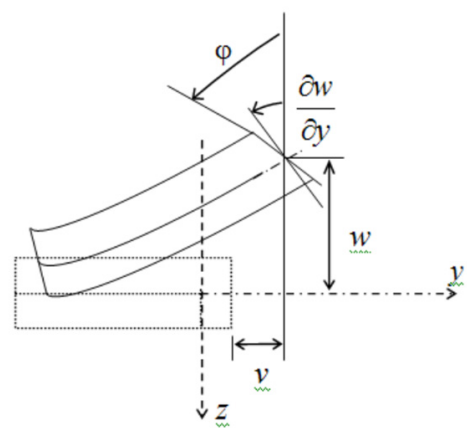

b)

Fig. 1. Reissner kinematics

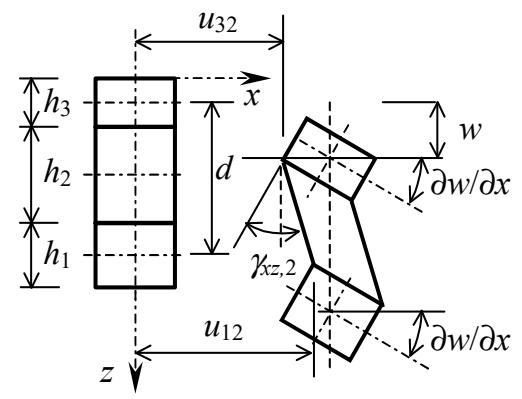

a)

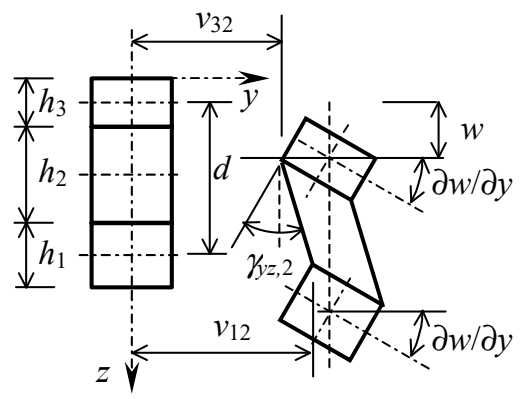

b)

Fig. 2. Geometry of shear deformation

Internal forces are expressed by terms:

$$
\begin{aligned}
& \mathbf{N}=\int_{-\left(\frac{1}{2} h^{(2)}+h^{(1)}\right)}^{-\frac{1}{2} h^{(2)}} \boldsymbol{\sigma} d z+\int_{-\frac{1}{2} h^{(2)}} \boldsymbol{\frac { 1 } { 2 } h ^ { ( 2 ) } + h ^ { ( 3 ) }} \boldsymbol{\sigma} d z, \\
& \mathbf{M}=\int_{\substack{-\left(\frac{1}{2} h^{(2)}+h^{(1)}\right) \\
\frac{1}{2} h^{(2)}}} \boldsymbol{\sigma} z d z+\int_{\frac{1}{2} h^{(2)}} \boldsymbol{\sigma} z d z, \\
& \mathbf{V}=\int_{-\frac{1}{2} h^{(2)}} \tau d z \text {. }
\end{aligned}
$$

The constitutive equations for a sandwich are in the form:

$$
\left(\begin{array}{l}
\mathbf{N} \\
\mathbf{M} \\
\mathbf{V}
\end{array}\right)=\left(\begin{array}{ccc}
\mathbf{A} & \mathbf{B} & 0 \\
\mathbf{C} & \mathbf{D} & 0 \\
0 & 0 & \mathbf{A}^{s}
\end{array}\right)\left(\begin{array}{c}
\boldsymbol{\varepsilon}_{m}^{0} \\
\mathbf{\kappa} \\
\boldsymbol{\gamma}
\end{array}\right),
$$

with stiffness coefficients: 


$$
\begin{aligned}
& A_{i j}=A_{i j}{ }^{(1)}+A_{i j}{ }^{(3)}, B_{i j}=\frac{1}{2} h^{(2)}\left(A_{i j}{ }^{(3)}-A_{i j}{ }^{(1)}\right), C_{i j}=C_{i j}{ }^{(1)}+C_{i j}{ }^{(3)}, \\
& D_{i j}=\frac{1}{2} h^{(2)}\left(C_{i j}{ }^{(3)}-C_{i j}{ }^{(1)}\right), \quad A_{i j}^{S}=E_{i j}^{S} h^{(2)}, i, j=4,5,
\end{aligned}
$$

where $A_{i j}, D_{i j}$ are coefficients of extension and bending stiffness matrix, $B_{i j}, C_{i j}$ are coefficients of extension-bending coupling stiffness matrix, $E_{i j}^{S}$ are the transverse shear moduli of the core.

\section{Free vibrations of sandwich plates}

The equations to determine the natural frequencies of the symmetric sandwich panel are used [1]:

$$
\begin{aligned}
& D_{11} \frac{\partial^{2} \Phi_{x}}{\partial x^{2}}+D_{66} \frac{\partial^{2} \Phi_{x}}{\partial y^{2}}+\left(D_{12}+D_{66}\right) \frac{\partial^{2} \Phi_{y}}{\partial x \partial y}-k^{s} A_{55}\left(\Phi_{x}+\frac{\partial w_{0}}{\partial x}\right)-I_{2} \frac{\partial^{2} \Phi_{x}}{\partial t^{2}}=0 \\
& \left(D_{12}+D_{66}\right) \frac{\partial^{2} \Phi_{x}}{\partial x \partial y}+D_{66} \frac{\partial^{2} \Phi_{y}}{\partial x^{2}}+D_{22} \frac{\partial^{2} \Phi_{y}}{\partial y^{2}}-k^{s} A_{44}\left(\Phi_{y}+\frac{\partial w_{0}}{\partial y}\right)-I_{2} \frac{\partial^{2} \Phi_{y}}{\partial t^{2}}=0 \\
& k^{s} A_{55}\left(\frac{\partial \Phi_{x}}{\partial x}+\frac{\partial^{2} w}{\partial x^{2}}\right)+k^{s} A_{44}\left(\frac{\partial \Phi_{y}}{\partial y}+\frac{\partial^{2} w_{0}}{\partial y^{2}}\right)-\rho_{m} h \frac{\partial^{2} w_{0}}{\partial t^{2}}=0
\end{aligned}
$$

where $k^{s}$ is the transverse shear deformation factor given by value $5 / 6$ :

$\rho_{m}=\frac{1}{h} \sum_{k=1}^{N} \rho_{k}\left(z^{(k)}-z^{(k-1)}\right), \quad I=\frac{\rho_{m} h^{3}}{12} \frac{1}{3} \sum_{k=1}^{N} \rho_{k}\left(z^{(k)}\right)^{3}-\left(z^{(k-1)}\right)^{3}$,

where $\rho_{k}$ is the mass density of the $k$ th layer.

For the simply supported plate let:

$w_{0}(x, y, t)=\mathrm{w}_{0}^{\circ} e^{i \omega_{m n} t}, \Phi_{x}(x, y, t)=\Phi_{x}^{\circ} e^{i \omega_{m n} t}, \Phi_{y}(x, y, t)=\Phi_{y}^{\circ} e^{i \omega_{m n} t}$,

where $m, n$ - are integers only, $\omega_{m n}$ - is natural angular velocity.

Ultimate length of sandwich panel depends on the ultimate frequency $f_{0, l i m}$ of dynamic loading affected to the structures:

$$
L_{0, \text { lim }}=\sqrt{\frac{\pi m^{2}\left(\sqrt{k_{s}^{2} A_{55}^{2} D_{11} h \rho_{m}+\pi^{2} D_{11} h^{2} \rho_{m}^{2} f_{0, \text { lim }}^{2}}-\pi D_{11} h \rho_{m} f_{0, \text { lim }}\right)}{2 k_{s} A_{55} h \rho_{m} f_{0, \text { lim }}}} .
$$

\section{Numerical solution of sandwich panels}

For the numerical solution, the simply supported panel with laminate facings was used. Panel length is $3250,4250,5250,6250,7100 \mathrm{~mm}$, nominal width is $1000 \mathrm{~mm}$. The thickness of the panel is 40,80 and $120 \mathrm{~mm}$. The thickness of laminate facings is $1 \mathrm{~mm}$, composed of eight layers of symmetric $[0 / \pm 45 / 90]_{\mathrm{s}},[0 / 90]_{2 \mathrm{~s}}$ and $[0 / 0]_{2 \mathrm{~s}}$ laminates, respectively. The thickness of each laminate layer is $0.125 \mathrm{~mm}$. Carbon fibers in epoxy matrix were considered [11], with the following characteristics: $E_{f}=230 \mathrm{GPa} ; E_{m}=3 \mathrm{GPa} ; v_{f}=0.3 ; v_{m}=0.3 ; \xi=0.6$; $\rho_{c}=1508 \mathrm{~kg} / \mathrm{m}^{3}$. Sandwich core, consisting of PUR foam, has material constants: $E_{P U R}=25 \mathrm{MPa} ; v_{P U R}=0.3 ; \rho_{P U R}=100 \mathrm{~kg} / \mathrm{m}^{3}$.

Firstly, it has been done the modal analysis of the sandwich panels with a thickness of 40,80 and $120 \mathrm{~mm}$, composed of eight layers of symmetric $[0 / \pm 45 / 90]_{\mathrm{s}},[0 / 90]_{2 \mathrm{~s}}$ and zero angles $[0 / 0]_{2 \mathrm{~s}}$ laminates as sandwich outer layers for $3250 \mathrm{~mm}$ panel length. 
Table 1 shows the first natural frequency depending on the variation of fiber reinforced angle of the laminate facings and the core thickness of the sandwich panel. The natural frequencies depend on the rotation of individual layers to the global coordinate system, while the lowest value of first natural frequency was obtained for the sandwich panel with [0/45/-45/90 $]_{\mathrm{s}}$ laminate faces and panel thickness $40 \mathrm{~mm}$. Dependence of the natural frequencies from its natural mode shape of vibration by various faces is shown in the Fig. 3 .

Table 1. First natural frequencies $f[\mathrm{~Hz}]$ of sandwich panels with length $L=3250 \mathrm{~mm}$

\begin{tabular}{|c|c|c|c|c|c|c|c|c|c|}
\hline \multirow{3}{*}{ Natural mode shape } & \multicolumn{2}{|c|}{ Laminate $[0 / 90]_{2 \mathrm{~s}}$} & \multicolumn{2}{c|}{ Laminate $[0 / \pm 45 / 90]_{\mathrm{s}}$} & \multicolumn{3}{c|}{ Laminate $[0 / 0]_{2 \mathrm{~s}}$} \\
\cline { 2 - 10 } & \multicolumn{2}{|c|}{ Thickness $[\mathrm{mm}]$} & \multicolumn{3}{c|}{ Thickness $[\mathrm{mm}]$} & \multicolumn{3}{c|}{ Thickness $[\mathrm{mm}]$} \\
\cline { 2 - 10 } & 40 & 80 & 120 & 40 & 80 & 120 & 40 & 80 & 120 \\
\hline 1 & 13.7 & 21.8 & 27.7 & 11.9 & 18.5 & 23.6 & 18.5 & 29.2 & 36.7 \\
\hline
\end{tabular}

Secondly, the modal analysis for various lengths of the sandwich panel with $[0 / 45 /-45 / 90]_{\mathrm{s}}$ laminate faces was made to find the limit length of the panel, which is sensitive to dynamic wind load with $f_{0, l i m}=5 \mathrm{~Hz}$. The limit length of sandwich panels with [0/45/-45/90] laminate faces was found for various thicknesses of the sandwich. For sandwich panel 40, 80 and $120 \mathrm{~mm}$ thick, the limit length is $5.0 \mathrm{~m}, 6.25 \mathrm{~m}$ and $7.1 \mathrm{~m}$, respectively. These types of sandwich panels are not sensitive to dynamic wind load under calculated limit lengths (Fig. 4).

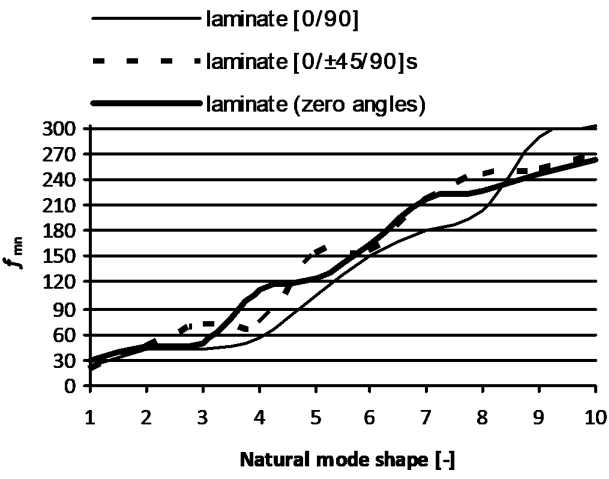

Fig. 3. Natural frequencies $[\mathrm{Hz}]$ of the first ten natural mode shapes of sandwich panels with $80 \mathrm{~mm}$ thickness

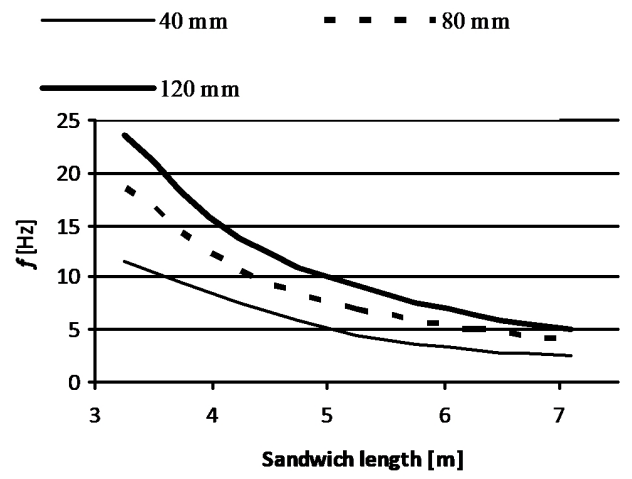

Fig. 4. First natural frequencies $[\mathrm{Hz}]$ of sandwich panels with symmetric $[0 / \pm 45 / 90]_{s}$ laminate facings versus sandwich length

\section{Conclusions}

The mechanical properties of sandwich panels with laminate faces were investigated. Computational program MATLAB was used to calculate the effective material properties of laminate faces $[12,13]$. The type of faces of a sandwich panel and the core thickness affect its natural frequencies. The first natural frequency of investigated laminate panels with the length $L=3250 \mathrm{~mm}$ is up to $f_{0, \text { lim }}=5 \mathrm{~Hz}$ (Table 1 ), therefore the panels are not sensitive to the dynamic wind load. The sandwich panels with [0/45/-45/90]s laminate faces and 40, 80 and $120 \mathrm{~mm}$ thick are not sensitive to dynamic wind load under their ultimate length $5.05 \mathrm{~m}, 6.25$ and $7.1 \mathrm{~m}$, respectively (Fig. 4).

\section{Acknowledgements}

This work was supported by the Scientific Grant Agency of the Ministry of Education of Slovak Republic and the Slovak Academy of Sciences under Projects VEGA 1/0374/19 and 1/0078/16. 


\section{References}

[1] Altenbach H., Altenbach J., Kissing W. Mechanics of Composite Structural Elements. Springer Verlag, Berlin, 2004.

[2] Luciano R., Barbero E. J. Formulas for the stiffness of composites with periodic microstructure. Journal of Solids Structures, Vol. 31, Issue 21, 1994, p. 2933-2944.

[3] Reddy J. N. Mechanics of Laminated Composite Plates and Shells: Theory and Analysis. Second Edition, CRC Press, Florida, 2004.

[4] Carrera E., Pagani A., Valvano S. Multilayered plate elements accounting for refined theories and node-dependent kinematics. Compos Part B, Vol. 114, 2017, p. 189-210.

[5] Murčinková Z., Novák P., Kompiš V., Žmindák M. Homogenization of the finite-length fibre composite materials by boundary meshless type method. Archive of Applied Mechanics, Vol. 88, Issue 5, 2018, p. 789-804.

[6] Vorel J., Urbanová S., Grippon E., Jandejsek I., Maršálková M., Šejnoha M. Multi-scale modeling of textile reinforced ceramic composites. Ceramic Engineering and Science Proceedings, Vol. 34, Issue 10, 2014, p. 233-245.

[7] Sladek J., Novak P., Bishay P. L., Sladek V. Effective properties of cement-based porous piezoelectric ceramic composites. Construction and Building Materials, Vol. 190, 2018, p. 1208-1214.

[8] Brischetto S. Convergence analysis of the exponential matrix method for the solution of 3D equilibrium equations for free vibration analysis of plates and shells. Compos Part B, Vol. 98, 2016, p. 453-71.

[9] Yhang L. W., Xiao L. N. Mechanical behavior of laminated CNT-reinforced composite skew plates subjected to dynamic loading. Compos Part B, Vol. 122, 2017, p. 219-230.

[10] Chandrashekara C. V., Suswaram P. E., Dharani J., Agarwal H., Raj Arjun S. I. Formulation of effective stiffness for predicting natural frequency of cracked beams. Vibroengineering Procedia, Vol. 19, 2018, p. 135-140.

[11] Piovar S., Kormanikova E. Statical and dynamical analysis of composite sandwich plates. Bulletin of the Transilvania University of Braşov Series I: Engineering Sciences, Vol. 4(53), Issues 1, 2011, p. $177-184$.

[12] Kormaníková E., Kotrasová K. Resonant frequencies and mode shapes of rectangular sandwich plate. Chemicke listy, Vol. 105, Issue 16, 2011, p. 535-538.

[13] Chen W., Meng Q., Hao H., Ciu J., Shi Y. Quasi-static and dynamic tensile properties of fiberglass/epoxy laminate sheet. Construction and Building Materials, Vol. 143, 2017, p. 247-259. 